\title{
Determination of seismic transport effects on buildings
}

\author{
D. Makovička ${ }^{1} \&$ D. Makovička Jr. ${ }^{2}$ \\ ${ }^{1}$ Czech Technical University in Prague, \\ Klokner Institute, Czech Republic \\ ${ }^{2}$ Static and Dynamic Consulting, Czech Republic
}

\begin{abstract}
Building structures in the vicinity of above-ground or underground transport lines are loaded by vibrations excited by the passage of motor vehicles or trains. These vibrations propagate as technical seismicity effects through the soil to the foundations of buildings in the vicinity of their source. Due to its tuning, the building structure usually amplifies the effects of technical seismicity. These vibration levels may have an impact on people working or living in the buildings, or on sensitive equipment installed in the buildings.

This paper deals with an experimental determination of the transport actions generated by various types of vehicles (trucks, trams, trains) in different conditions (roads, railways). The purpose of the paper is to formulate actions specific for various types of transport conditions as a basis for the design of structures.

Keywords: technical seismicity, transport effect, vibration measurement.
\end{abstract}

\section{Introduction}

The character of the vibrations generated by transport depends particularly on vehicle weight, driving speed, how the vehicles move and in what way and direction. Another parameter is the "evenness" of the vehicle trajectory, in terms of whether it concerns the quality of the pavement surface or the horizontal and vertical railway alignment, the way in which the rails are fastened, the composition of the pavement courses, etc. The magnitude of the vibrations is influenced not only by the vibration parameters at the source but also by the composition of the environment on the way from the source to the threatened 
building structure, in particular the composition of the geological environment and its mechanical properties, i.e. stiffness, wave propagation velocity, distancedependent damping, etc. Last but not least, the magnitude of the vibration may be amplified or damped by the building structure itself and by its foundations, in particular the frequency tuning of the threatened structure.

As a rule, the intensity of vibrations propagating through the soil is higher than the intensity of vibrations due to acoustic phenomena. As far as safety is concerned, this level of vibrations generated by standard traffic is of no significance for current buildings, with the exception of historical or decrepit structures. Major cracks may originate due to the passage of very heavy vehicles or the operation of construction plant (such as vibration rollers) on new construction sites in the proximity of existing buildings.

Before transport-generated vibrations begin to cause damage to threatened structures a more serious problem may arise, i.e., the impact of vibrations on the people dwelling within these structures. Vibrations of this type usually exceed the safety limits specified by hygienic standards (see Fig. 1) well before cracks and fissures originate in the structure.

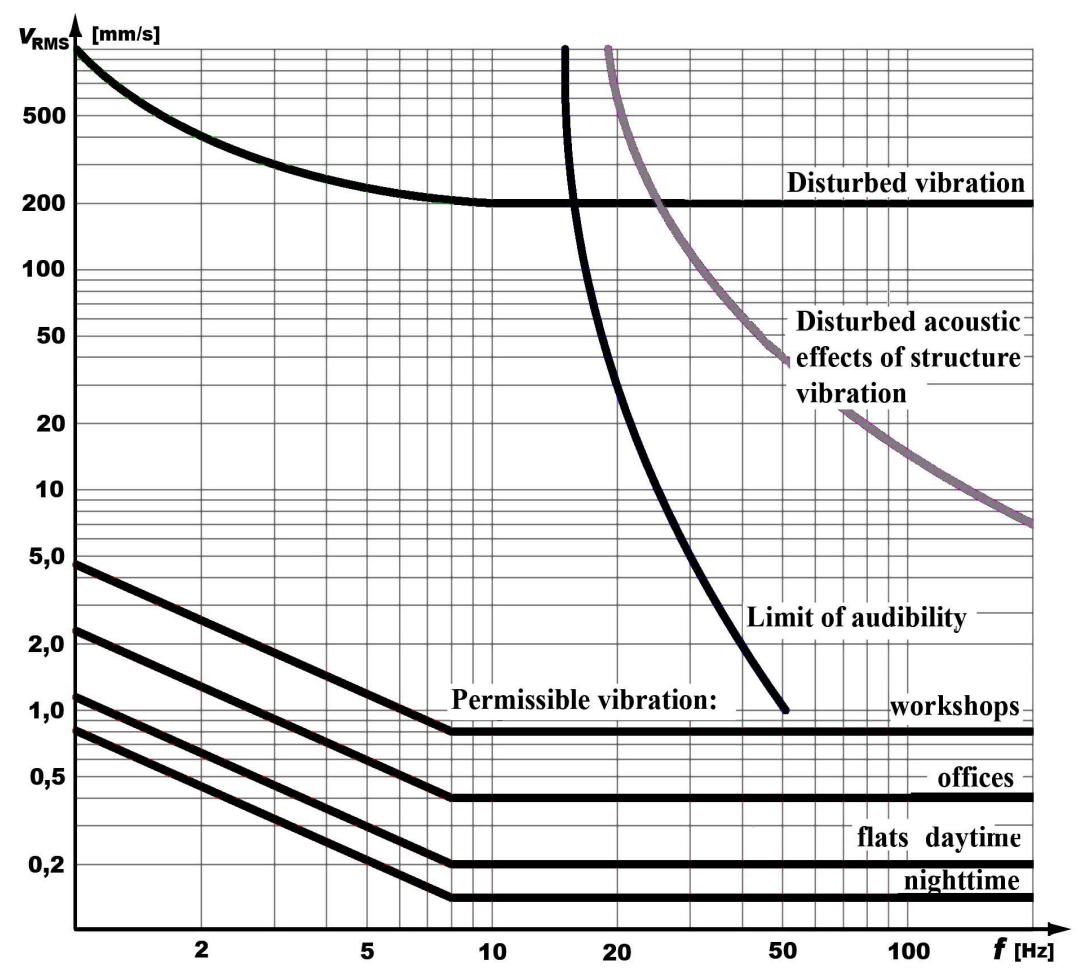

Figure 1: Comparison of hygienic limit values [4] for disturbed and permissible vibration. 


\section{Road transport}

To ascertain the laws and common principles governing transport-generated vibrations a number of measurements of vibrations were carried out in the proximity of roads and in (usually low-rise) buildings in their environs. Selected maximum values measured at various locations are given in Table 1.

Table 1: Comparison of the acceleration amplitude level of transportgenerated vibrations on various locations.

\begin{tabular}{|c|c|c|c|c|c|}
\hline $\begin{array}{l}\text { Vibration } \\
\text { source }\end{array}$ & Location & \multicolumn{2}{|c|}{$\begin{array}{c}\text { Acceleration } \\
\text { interval apeak } \\
{\left[\mathrm{mm} / \mathrm{s}^{2}\right]} \\
\end{array}$} & $\begin{array}{l}\text { Measurement } \\
\text { distance from } \\
\text { source [m] }\end{array}$ & $\begin{array}{l}\text { Measurement } \\
\text { location }\end{array}$ \\
\hline Tramway & \multirow{2}{*}{$\begin{array}{l}\text { Older main road, } \\
\text { Prague }\end{array}$} & 18 & 22 & 12 & Footway curb \\
\hline $\begin{array}{l}\text { Heavy } \\
\text { truck }\end{array}$ & & 12 & 13 & 5 & Footway curb \\
\hline \multirow{4}{*}{ Subway } & Prague 4, Pankrác & 90 & 120 & 8 & $\begin{array}{c}\text { Building } \\
\text { foundations } \\
\text { above subway }\end{array}$ \\
\hline & \multirow{2}{*}{ Prague 5, Radlice } & 30 & 65 & 2 & Station platform \\
\hline & & 15 & 17 & 3 & \begin{tabular}{|c|} 
Tunnel lining \\
\end{tabular} \\
\hline & Prague 5, Hůrka & 121 & 690 & 15 & Pile head \\
\hline \multirow{7}{*}{$\begin{array}{l}\text { Heavy } \\
\text { truck }\end{array}$} & \multirow{3}{*}{ New main road } & 12 & 16 & 3 & Local road \\
\hline & & 13 & 14 & 8 & Staircase \\
\hline & & 21 & 23 & 8 & House, 1st floor \\
\hline & \multirow{4}{*}{ Local village road } & 14 & 19 & 8 & $\begin{array}{c}\text { House, ground } \\
\text { floor } \\
\end{array}$ \\
\hline & & 30 & 36 & 8 & House, 1st floor \\
\hline & & 19 & 23 & 1 & Road curb \\
\hline & & 12 & 18 & 10 & Staircase \\
\hline Train & \multirow{3}{*}{$\begin{array}{l}\text { Railway and } \\
\text { parallel main road } \\
\text { outside the city }\end{array}$} & 9 & 9 & 500 & \multirow{3}{*}{$\begin{array}{c}\text { Test foundation } \\
\text { in non-built-up } \\
\text { area }\end{array}$} \\
\hline $\begin{array}{l}\text { Heavy } \\
\text { truck }\end{array}$ & & 2 & 8 & 500 & \\
\hline Bus & & 2 & 6 & 500 & \\
\hline
\end{tabular}

These measured vibration maxima are documented with a few selected vibration histories and their FFT spectra. Fig. 2 (Local village road in Table 1) shows the measured vibration levels in close proximity to the carriageway during the passage of a fully-loaded truck travelling at $20-30 \mathrm{~km} / \mathrm{h}$ along a local bituminous road with relatively small surface irregularities up to $10 \mathrm{~mm}$. Measurements were also performed on the ground floor of a new family house, without a basement, next to the road, in the close proximity of the front wall, and finally also on the 1st floor level of the same house above the ground floor measuring site. These measurements confirm the well-known fact that any building structure amplifies the vibrations from the road on its own natural frequencies. The transmission of traffic-generated vibrations through the subsoil to the building structure must be analyzed in detail, as a rule, although this vibration amplitude level is very low for the first group of limit states. 
Another example involves a two-storey family house in the proximity of a new very high quality main road during the passage of heavy international transport trucks (TIR) the house at approx. $40-50 \mathrm{~km} / \mathrm{h}$. The measurements were made both on the footway next to the carriageway and on the ground floor and the 1st floor levels of the family house in the proximity of the outside walls. A comparison of the measured vibration levels (Table 1) shows obvious vibration amplitude amplification inside the house. This vibration amplification concerns the frequency components corresponding with the natural frequencies of the specific building, naturally different from the preceding case.

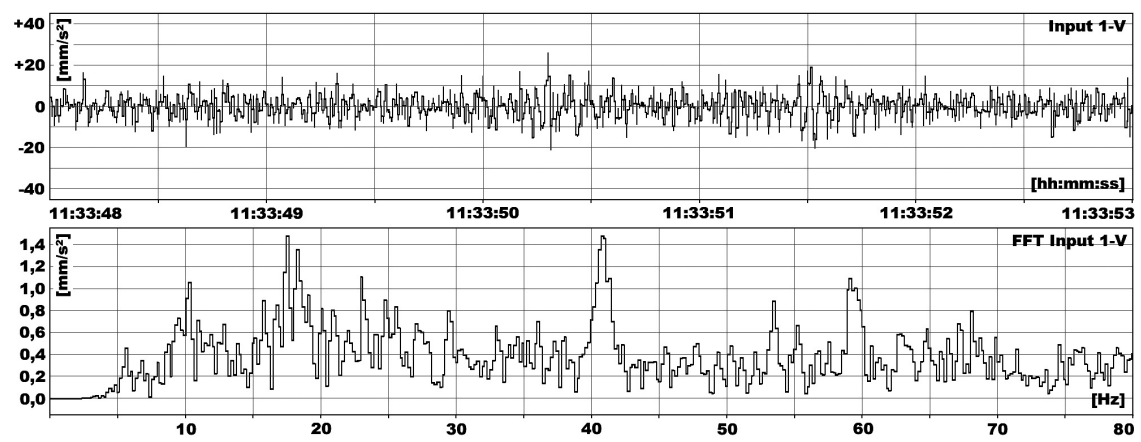

Figure 2: $\quad$ Time duration and FFT spectrum of vertical vibration of the action of a truck on a local village road.

The next example concerns the vibrations measured on the curb of an older good-quality urban road in Prague carrying road and tram transport, generated by the passage of heavy freight transport at $50-60 \mathrm{~km} / \mathrm{h}$ and the passage of trams at $40-50 \mathrm{~km} / \mathrm{h}$ (see Table 1). These measurements show that the amplitude level of transport-generated vibrations on a good quality carriageway, whether of a wellmaintained older road or of a new road, is comparable.

Table 2: Comparison of effective vibration acceleration levels $\left(\mathrm{mm} / \mathrm{s}^{2}\right)$ produced by a heavy truck and a bus driving at different speeds along an uneven pavement.

\begin{tabular}{|l|c|c|c|c|}
\hline Site & \multicolumn{2}{|c|}{$25 \mathrm{~km} / \mathrm{h}$} & \multicolumn{2}{c|}{$50 \mathrm{~km} / \mathrm{h}$} \\
\hline & Bus & Track & Bus & Track \\
\hline $\begin{array}{l}\text { Ground near front } \\
\text { façade }\end{array}$ & 20.5 & 19.9 & 64.5 & 33.2 \\
\hline $\begin{array}{l}\text { Outside wall at ground } \\
\text { level }\end{array}$ & 11.2 & 10.1 & 30.9 & 15.7 \\
\hline Ground floor, centre & 20.3 & 20.8 & 62.9 & 30.1 \\
\hline 1st floor, centre & 35.0 & 37.3 & 96.2 & 46.7 \\
\hline \multicolumn{2}{|l|}{ Note: The bus was provided with air-cushioning, the truck with steel leaf springs } \\
\hline
\end{tabular}


For a comparison with foreign experience, Table 2 (from [3]) presents the results of Canadian measurements of a heavy truck and a bus of identical weight category along an uneven carriageway. European conditions are characterized by the diagram in Fig. 3 for various types of passage of heavy trucks and tractors along standard carriageways [1]. A comparison of the two foreign materials with our experience reveals that the foreign results concern mostly uneven, possibly unpaved road surfaces. In the case of urban or newer higher class roads, these vibrations are lower.

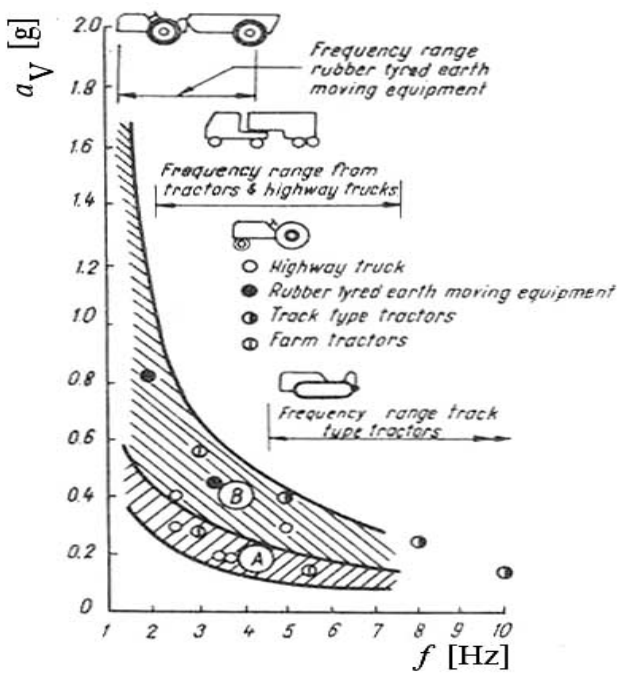

Figure 3: Characteristic vibration of various tracks crossing.

Nevertheless, a comparison of the results of all above-mentioned measurements enables us to assume that the estimates of the effect of transport on building structures are approximate and variable. It is therefore recommended to improve the accuracy of the estimates, particularly for more important structures or buildings of extensive plan or height, especially housing estates, hotels, offices and school buildings, by measurements in the specific conditions of the given site.

Generally speaking, we can conclude that the frequencies of the vibrations produced by road transport propagating through the ambient environment to the nearby buildings vary approximately between 5 and $25 \mathrm{~Hz}$. Their amplitudes vary between 0.005 and $2 \mathrm{~m} / \mathrm{s}^{2}$ in terms of acceleration, and between 0.05 and $25 \mathrm{~mm} / \mathrm{s}$ in terms of velocity.

The dominant vibration frequencies and amplitudes of building excitation depend on a number of factors, in the first place on the pavement, vehicle weight and design, its speed and the manner of driving (e.g. stopping), type, composition, consolidation and moisture content of the road subsoil and the route of the propagation of the vibrations to the building, road distance from the building, season (upper ground stratum frozen, dry, sodden), etc. These factors 
are mutually interdependent and it is impossible to define simple relations among them.

For example, the influence of vehicle travel speed is connected with pavement evenness. Generally speaking, the more uneven the pavement surface, the greater the effect of vehicle speed on the excited vibration amplitudes. Similarly vehicle drive, e.g., vibrations generated by stopping, also depends on initial vehicle speed and pavement evenness. In the case of low velocities and a good quality pavement surface, the manner of vehicle stopping is practically insignificant in comparison with high-speed roads or uneven pavements. Table 2 reveals that the effects of the heavy truck and of the bus at a speed of $25 \mathrm{~km} / \mathrm{h}$ are comparable, while at $52 \mathrm{~km} / \mathrm{h}$ the truck effects are almost double those of the bus.

The amplitudes of the excitation vibrations and their dominant frequencies also depend on subsoil type and consolidation. The stiffer the subsoil and the lower the wave propagation damping in the subsoil, the higher the vibration amplitudes transferred to the threatened structure. During vibration propagation through the subsoil the natural frequencies of soils - the strata covering the base rock - become significant. In the conditions of the Czech Republic, the usual soil cover on top of the bedrock is $2-4 \mathrm{~m}$ in thickness, in which case the natural frequencies of the soil on top of the bedrock may approach the natural frequencies of the buildings (their walls and floors). In that case the transmission of transport-generated vibrations to the building structures is increased by the resonance effect.

\section{Rail transport}

The seismic load produced by surface or subsurface rail transport manifests itself, as in the case of road transport, as a kinematic load on the building foundations in the proximity of these transport routes [2]. Similarly as in road transport, the characteristics of the excitation vibrations on individual sites may differ significantly according to vehicle type, travel route, driving method, etc. The character of the excitation vibrations generated by rail transport corresponds with the passage of a train across track irregularities and the transverse sway of the vehicles due to the leeway between the wheel and the rail. The measured histories of these effects usually make it possible to identity the number of wagons in a train, the effect of the number of axles manifesting itself on the measurement records during the passage of the train past the measurement site by individual groups of amplitudes and subsequent fading.

The rate of differences in the measured vibrations produced by the passage of underground trains is revealed by a comparison of a few selected records and their frequency spectra in Prague conditions.

Fig. 4(a) shows a record of the measurements on Line $\mathrm{C}$ of the Prague Underground Railway in Pankrác. Fig. 4(b) shows a record of the measurements on a newer section of Line B in Radlice. For the sake of comparison both sites are included in Table 1 together with the vibrations measured on Line B near Hůrka station, where the track emerges from the tunnel to the bridge structure, 
where the magnitude of the vibrations is also influenced by a change in the stiffness of the track subbase. The amplitudes of the vibrations generated by the passage of underground trains along the tunnel are approximately in the ratio of $2: 1$ (see Table 1), though the frequency structure of the vibrations is entirely different. The vibrations measured on the sites next to the underground lines passing approximately at the same depth below ground level (shallow lines) manifest themselves by different dominant frequencies - from 35 to $65 \mathrm{~Hz}$ in case of the older Line C, and from 48 to $80 \mathrm{~Hz}$ in case of the newer section of Line B. The structure of the tunnel tube and of the permanent way obviously exercises a dominant influence on the character of the excitation frequencies.
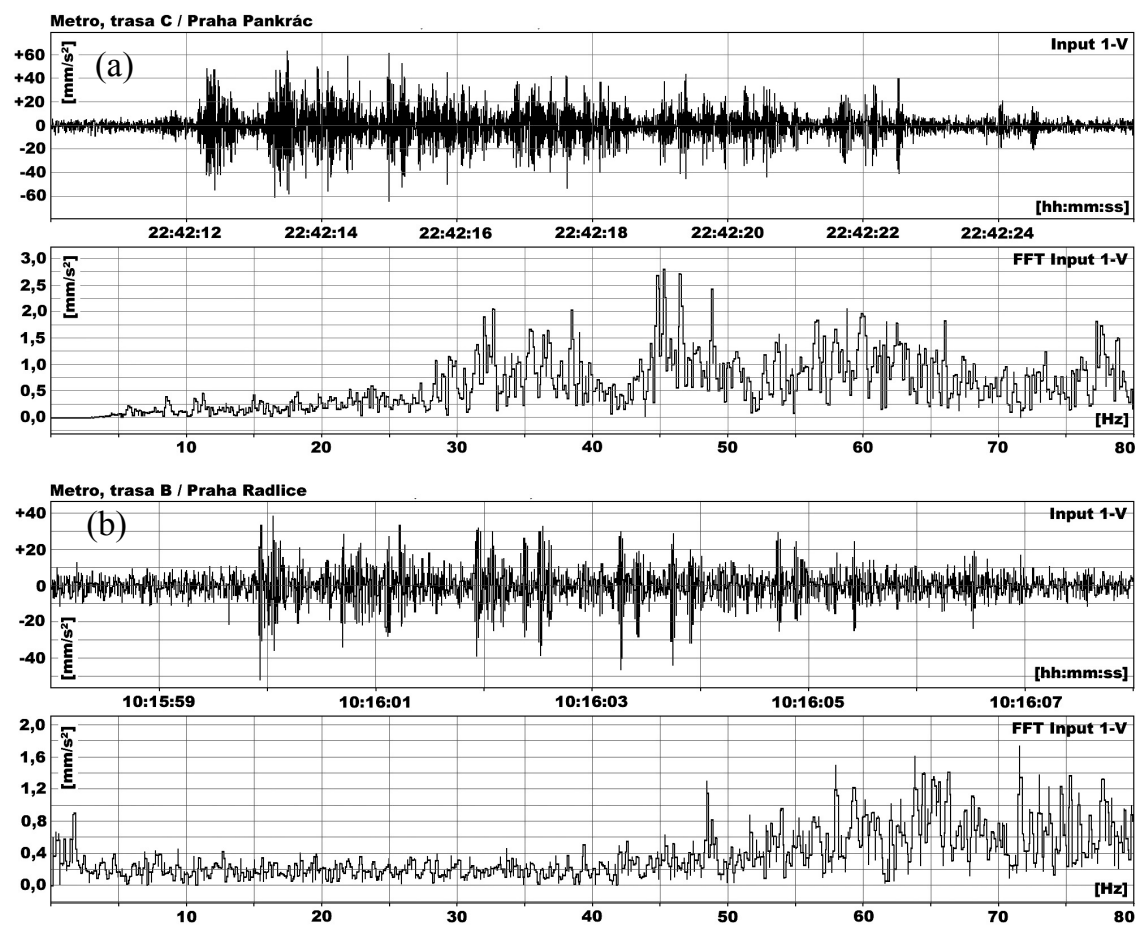

Figure 4: Time duration and FFT spectrum of vertical vibration of the action of a train, measured on a building foundation on subway Line C (a) and on a station platform on Line B (b).

In the course of the transmission of vibrations from the deep underground lines to the ground surface, the amplitude excitation level is usually reduced. For instance, the construction of the Hilton Hotel in Prague was preceded by vibration measurements on the level of the underground tunnel lining between stations and on the test foundation on the free site. An example of the frequency spectra of the measured vertical vibrations is shown in Fig. 5. A comparison of the response level at the tunnel structure level and at ground level reveals that the 
frequency structure of the excitation signal in the course of its passage through the geological environment changes due to strata thickness, distance from the source, etc. The spectrum of the test foundation measurements also contains the frequencies of the location of this foundation on the subsoil (Fig. 5 shows the peak of the natural frequency of the foundation vibrations on the subsoil at a rate of some $69 \mathrm{~Hz}$ ). This frequency is insignificant for the assessment of the excitation vibration of the future building.
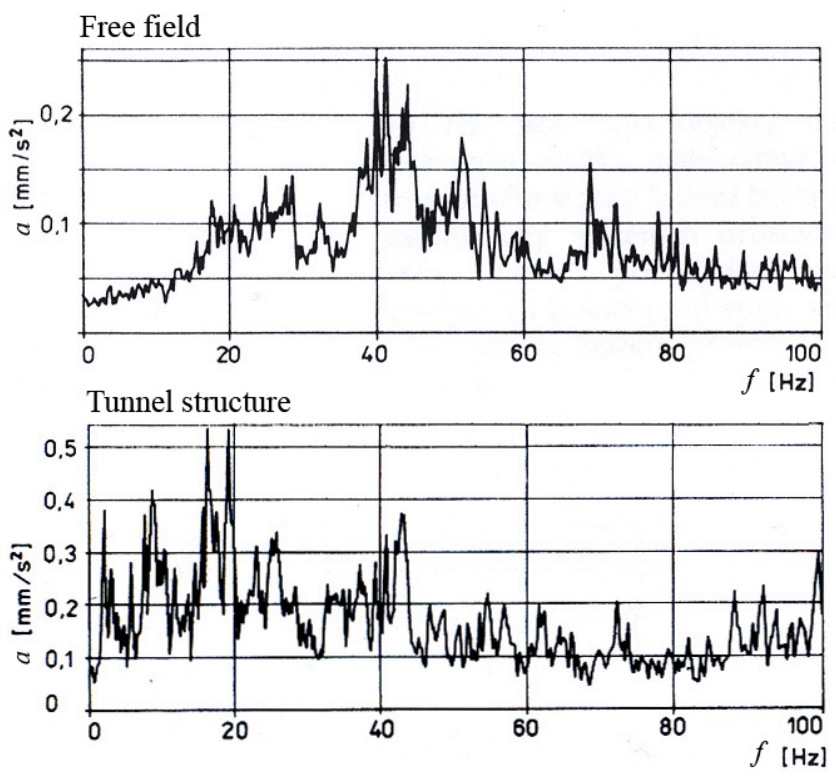

Figure 5: Comparison of measured spectra of free field and tunnel structure vibration.

When considering the effects of the movement of a train along new lines on the magnitude of the excited vibrations, the train stopping at the station results in an approximately ninefold increase in the vibration amplitudes in comparison with a smooth train run through the station.

When monitoring vibrations in the rail track and in the tunnel tube structure, the rail track vibrations need not always be higher than those of the tunnel or station structure; it depends on the spectrum of the natural frequencies of the respective tunnel structure (by analogy with the vibrations transmission of vibrations from the pavement to the nearby buildings in the case of road transport). As a result, the rail track vibrations may be increased or reduced in the frequencies corresponding with the natural tunnel frequencies.

Generally speaking, we can conclude that in Prague conditions effective vibrations (effective vibration acceleration) due to train travel on the underground railway are of the order of tenths of $\mathrm{mm} / \mathrm{s}^{2}$, if these vibrations propagate through the geological environment over greater distances and from major depths. Momentary peak amplitudes of vibration acceleration vary within 
units to tens of $\mathrm{mm} / \mathrm{s}^{2}$. The dominant frequency components of the vibrations vary from $40 \mathrm{~Hz}$ upwards. In building foundations connected firmly with the underground railway structure e.g. through RC structures, concrete grout escaped from the foundations, base rock, an increase in the amplitudes of the excitation vibrations from this boundary is obvious.

\section{Influence of landscaping on vibration transmission}

Most of the total energy from shallow or surface sources (whether transport or stationary sources, such as machine foundations, etc.) is transmitted to the ambient structures in the form of surface waves of the ground or of various material subsoil strata. The main part, approx. $67 \%$, consists in Rayleigh surface waves, with $26 \%$ falling to shear waves and $7 \%$ to longitudinal waves.

Due to the surface waves, vibration propagation to building structures is decisively influenced by the form of connection of the carriageway and the threatened building by a paved surface (pavement, concrete surfaces) or by an unpaved surface (lawns, gardens).

The effect of this type of connection on vibration propagation from the carriageway to the building structures is shown by the yielded experimental results of the measurements of the effect of a vibration roller on ambient buildings, firmly connected with the road by paved footways or separated from the footway by a $5 \mathrm{~m}$ green strip. In the case of paved surfaces, the vibrations were approximately twice as high (Fig. 6).

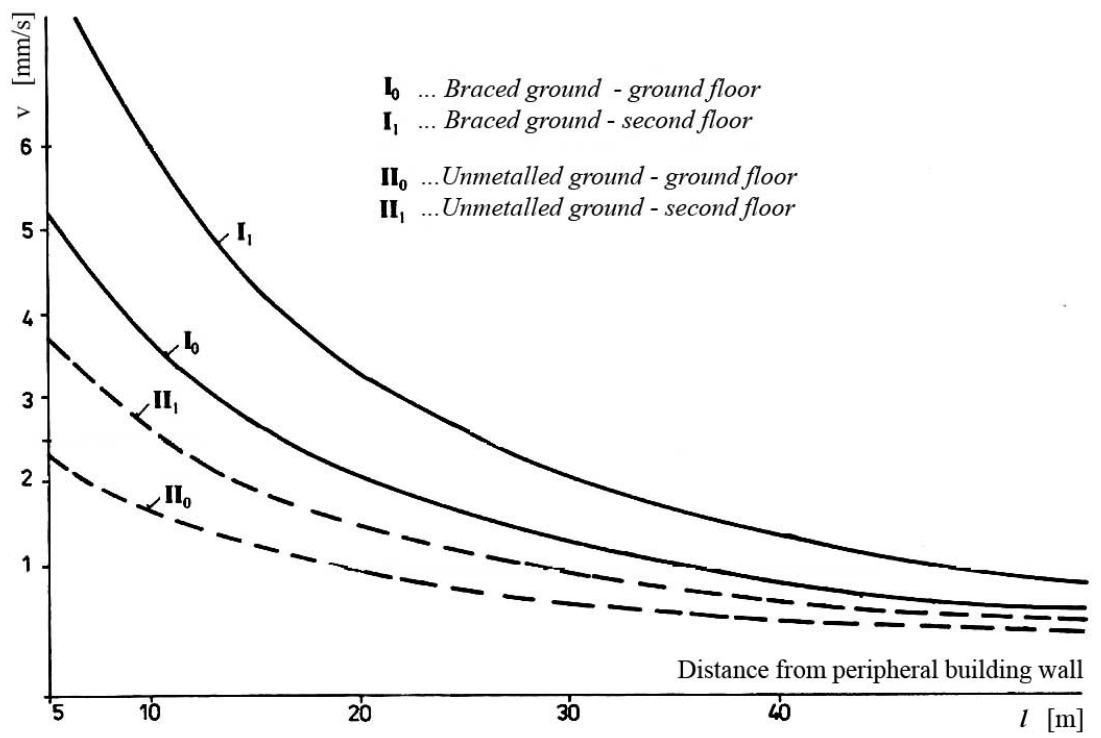

Figure 6: Measured vibration velocity in a building for various distances of the roller from a two-storey masonry structure. 


\section{Conclusion}

The purpose of this paper was to compare the effects of surface and subsurface transport on the building structures in their vicinity, and an informative survey of their amplitude and frequency characteristics, including possible modifications to these excitation vibrations due to the response of the structure to their effect. The problem is highly complicated, and does not always permit an explicit answer without a detailed analysis, because both the excitation character and the response of the structure depend on a number of parameters not only at the source and at the threatened structure but also en route from the source to the threatened structure.

For these reasons, and in accordance with foreign experience it seems most adequate to measure the vibration level at the source, en route or at the threatened structure. If the structure is under construction, it is possible to make the measurements at its foundations or in their close proximity. The measurements will be followed by an assessment of the response of the threatened structure, and possibly by a proposal of measures aimed at reducing the vibrations of the whole structure or a part of it.

The response values measured on individual sites need not be significantly similar; on the contrary, they may differ considerably. The vibration values given here may, consequently, be considered as a first approach to actual values of a specific structure in specific conditions.

\section{Acknowledgements}

This research was supported as a part of GA projects No. 103/06/1521 and CZ.04.3.07/3.2.01.3/3323 for which the authors would like to thank the Grant Agency of the Czech Republic, the European Social Fund, the Capital City of Prague and the State Budget of the Czech Republic.

\section{References}

[1] Major, A., Dynamics in Civil Engineering. Akadémiai Kiadó, Budapest 1980.

[2] Makovička, D. \& Makovička, D., Jr., Response analysis of a building loaded by technical seismicity propagating from a tube railway structure, Earthquake Resistant Structures V, ed. Brebbia, C.A.:, WIT Press, Southampton, 2005, pp. 675-684.

[3] Osama Hunaidi, Traffic Vibrations in Buildings, National Research Council of Canada, No. 39, June 2000.

[4] ISO 2631-2:1989, Evaluation of human exposure to whole-body vibration Part 2: Continues and shock-induced vibration in buildings (1 to $80 \mathrm{~Hz}$ ). 